\title{
Bioprospecção de isolados de Trichoderma spp. para o controle de Rhizoctonia solani na produção de mudas de pepino
}

\author{
Cleusa Maria Mantovanello Lucon(1), Claudia Mitsue Koike(1), Alice Ishida Ishikawa(1), \\ Flávia Rodrigues Alves Patrício(2) e Ricardo Harakava(1)
}

(1)Instituto Biológico, Centro de Pesquisa e Desenvolvimento de Sanidade Vegetal, Avenida Conselheiro Rodrigues Alves, no 1252, CEP 04014-002 São Paulo, SP. E-mail: mantova@biologico.sp.gov.br, claumisk@bol.com.br, ishikawa@unisat.com.br, harakava@biologico.sp.gov.br (2)Instituto Biológico, Centro Experimental Central do Instituto Biológico, Caixa Postal 70, CEP 13001-970 Campinas, SP. E-mail: flavia@biologico.sp.gov.br

\begin{abstract}
Resumo - O objetivo deste trabalho foi selecionar e identificar isolados de Trichoderma spp. para o controle do tombamento causado por Rhizoctonia solani (AG-4) em plântulas de pepino (Cucumis sativus L.), além de avaliar o efeito de concentrações crescentes e de combinações dos isolados mais eficientes no controle da doença. Os experimentos foram conduzidos em casa de vegetação, com 490 isolados. O tombamento das mudas foi avaliado uma semana após a aplicação à base das plântulas de substrato infestado com antagonista (1\%) e patógeno (1\%). Os doze isolados que proporcionaram mais de $85 \%$ de redução da doença foram testados em concentrações crescentes para o controle do patógeno (1\%): 0,5, 1, 2, 3 e 4\%. Também foi avaliado o efeito das combinações dos cinco isolados mais promissores. Os isolados mais efetivos foram identificados pelo sequenciamento da região espaçadores internos transcritos (ITS) do DNA ribossômico. Dos 490 isolados testados $44(9 \%)$ reduziram o tombamento. As concentrações de antagonistas superiores a $2 \%$ foram as mais efetivas no controle da doença. Apenas duas combinações resultaram no aumento do controle da doença. Os isolados mais efetivos foram identificados como T. hamatum (IB08, IB30, IB60), T. harzianum (IB34, IB35), T. atroviride (IB13), T. spirale (IB16, IB24) e T. asperellum (IB44). Não foi possível a identificação da espécie de três isolados.
\end{abstract}

Termos de indexação: Cucumis sativus, antagonistas, controle biológico, método de seleção, tombamento.

\section{Bioprospection of Trichoderma spp. isolates to control Rhizoctonia solani on cucumber seedling production}

\begin{abstract}
The objective of this work was to select and identify Trichoderma spp. isolates for the control of Rhizoctonia solani (AG-4) damping-off on cucumber (Cucumis sativus L.) seedlings, as well as to evaluate the effects of increasing concentrations and different combinations of the most efficient isolates in the disease control. The experiments were carried out in a greenhouse with 490 isolates. The disease on cucumber seedlings was evaluated one week after the application of a commercial substrate infested with both antagonist (1\%) and pathogen (1\%) to the seedlings' root collar. The twelve isolates that conferred more than $85 \%$ of disease reduction were further evaluated in pathogen control $(1 \%)$ at the concentrations $0.5,1,2,3$ and $4 \%$. The effect of combining five of the most promising isolates in disease control was also evaluated. The most effective isolates were identified through the sequencing of the ribosomal internal transcribed spacers (ITS) region. Out of the 490 isolates tested $44(9 \%)$ caused reduction of damping-off. Antagonist concentrations higher than $2 \%$ conferred the most effective disease control. Only two combinations of isolates resulted in increased disease control. The most effective isolates were identified as T. hamatum (IB08, IB30, IB60), T. harzianum (IB34, IB35), T. atroviride (IB13), T. spirale (IB16, IB24) and T. asperellum (IB44). Three isolates could not be identified at species level.
\end{abstract}

Index terms: Cucumis sativus, antagonists, biological control, selection method, damping-off.

\section{Introdução}

Rhizoctonia solani é um importante fitopatógeno de solo e causa perdas em diversas culturas de importância econômica, inclusive hortaliças (Faltin et al., 2004). Como esse patógeno tem propensão a atacar tecidos jovens, ele causa tombamento de plântulas na pré ou pós-emergência. Os viveiros são especialmente vulneráveis e apresentam as maiores perdas infligidas pelo patógeno (Lewis \& Lumsden, 2001).

$\mathrm{O}$ fungo $R$. solani pode ser introduzido em solos ou substratos em qualquer etapa do plantio, tanto via sementes como por meio de substratos contaminados (Lewis \& Lumsden, 2001). Trata-se de um patógeno de difícil controle, em razão da produção de escleródios 
que garantem a sua sobrevivência em condições ambientais adversas, pois o patógeno pode viver saprofiticamente na matéria orgânica do solo e possui um grande número de hospedeiros (Faltin et al., 2004).

As principais formas de controle desse patógeno são o uso de fumigantes e o tratamento de sementes com fungicidas (Goulart, 2002; Fravel \& Lewis, 2004). Entretanto, segundo Lewis \& Lumsden (2001), nos Estados Unidos, as perdas em viveiros podem chegar a $10 \%$ da produção, mesmo com uso do tratamento químico.

O uso de antagonistas para o controle de fitopatógenos tem sido bastante investigado nas últimas décadas, por vários motivos, principalmente pelos problemas ambientais e de saúde humana decorrentes do uso indiscriminado de agrotóxicos (Grigoletti Júnior et al., 2000; Peres et al., 2007).

Espécies do gênero Trichoderma vêm sendo utilizadas com sucesso no controle de fitopatógenos de solo, por serem capazes de proteger plantas por meio de diferentes mecanismos de ação (parasitismo, antibiose, competição e indução de resistência), e por colonizar eficientemente o substrato e o sistema radicular de várias espécies de plantas (Harman et al., 2004; Harman, 2006; Woo et al., 2006). Além disso, esse gênero está entre os microrganismos mais resistentes às toxinas e produtos químicos naturais e sintetizados pelo homem, capazes até mesmo de degradar alguns desses compostos, tais como hidrocarbonetos e pesticidas (Harman et al., 2004; Harman, 2006; Woo et al., 2006). Outra importante característica desse gênero é que muitas de suas linhagens são produtoras prolíficas de esporos e de poderosos antibióticos (Woo et al., 2006).

Em razão da produção de mudas de hortaliças ser uma das etapas mais importantes do sistema produtivo, pois dela depende o desempenho final das plantas nos canteiros de produção (Marques et al., 2003), a aplicação de agentes de biocontrole em sementes ou substratos pode ser uma forma eficiente de proteger plântulas contra $R$. solani. Além disso, as condições que favorecem a doença, na etapa de produção de mudas, também podem favorecer os agentes biológicos introduzidos.

Embora os caracteres morfológicos continuem sendo utilizados como método primário para a identificação de isolados de Trichoderma sp., existem dificuldades e controvérsias na definição segura das espécies morfológicas desse gênero. Segundo Druzhinina \&
Kubicek (2005), esse fato tem ocasionado o emprego incorreto do nome das espécies comumente utilizadas para a indústria e para o biocontrole de fitopatógenos. Para evitar esse problema, Druzhinina et al. (2005) desenvolveram um método de identificação, no nível de gênero e espécie, fácil e rápido de ser utilizado, pois se baseia na comparação das sequências dos espaçadores internos transcritos (ITS) 1 e 2 do rDNA, obtidas de cada isolado, com as encontradas em um banco de dados online.

O objetivo deste trabalho foi selecionar isolados de Trichoderma spp. capazes de controlar o tombamento causado por $R$. solani (AG-4) em plântulas de pepino, bem como testar o efeito da aplicação de diferentes concentrações e combinações de alguns dos melhores isolados no controle da doença e identificá-los em nível de espécie.

\section{Material e métodos}

$\mathrm{Na}$ fase inicial do estudo, foram testados 490 isolados de Trichoderma spp., pertencentes à coleção de culturas do Laboratório de Bioquímica Fitopatológica do Instituto Biológico. O isolado de Rhizoctonia solani AG-4 foi cedido pelo Laboratório de Fitopatologia, do Centro Experimental Central do Instituto Biológico, em Campinas, SP.

Os propágulos do antagonista e do patógeno foram produzidos pela deposição de um disco de $5 \mathrm{~mm}$ de diâmetro de meio batata-dextrose-ágar (BDA), com as estruturas propagativas dos potenciais antagonistas ou do patógeno, em $10 \mathrm{~g}$ de grãos de arroz (com Trichoderma) ou trigo (com $R$. solani) previamente umedecidos e esterilizados. As culturas foram incubadas por sete dias em incubadora tipo BOD regulada para $27^{\circ} \mathrm{C}$, equipada com lâmpadas fluorescentes de luz branca e fria, com fotoperíodo de 8/16 horas (claro/ escuro).

Todos os ensaios foram realizados em casa de vegetação. Sementes de pepino, cultivar Rubi, foram plantadas em $300 \mathrm{~g}$ de substrato comercial para a produção de mudas (Plantmax $\mathrm{Ht} /$ Eucatex Agro), em sacos pretos de polietileno de $12 \mathrm{~cm}$ de largura por $12 \mathrm{~cm}$ de altura. Duas semanas após a germinação das sementes, foi feita a deposição, na base das plântulas, de $50 \mathrm{~g}$ de substrato Plantmax Ht misturado com $0,5 \mathrm{~g}$ de grãos de trigo colonizados com $R$. solani $(1 \%) \mathrm{e}$ $0,5 \mathrm{~g}$ de grãos de arroz colonizados com o antagonista (1\%). Após a incubação por uma semana em sacos de 
plástico transparentes, à temperatura ambiente, essas misturas foram depositadas na base das plântulas de pepino com duas semanas de idade. A avaliação foi realizada após uma semana, por meio da contagem do número de plântulas que sobreviveram em cada tratamento.

Foram realizados dez ensaios para testar os 490 isolados de Trichoderma spp. O delineamento experimental utilizado nesses ensaios foi $o$ inteiramente ao acaso, com 51 tratamentos cada, cinco repetições e cinco plantas por parcela. Os tratamentos foram constituídos por 49 isolados e duas testemunhas: uma sem adição de microrganismos e outra só com a adição do patógeno. Os dados de percentagem do número de plântulas sobreviventes foram transformados para $\operatorname{arc} \operatorname{sen}(\mathrm{x} / \mathrm{n})^{0,5}$ e submetidos à análise de variância. As médias foram comparadas pelo teste de Tukey, a 5\% de probabilidade.

Realizou-se mais um ensaio, também em casa de vegetação, para avaliar o efeito de diferentes doses dos 12 isolados de Trichoderma spp. que proporcionaram redução superior a $85 \%$ no tombamento de plântulas. Esses 12 isolados haviam sido selecionados entre os 44 que reduziram o tombamento na etapa anterior do estudo. Em $50 \mathrm{~g}$ de substrato Plantmax Ht, foi feita a adição de $0,5 \mathrm{~g}$ de grãos de trigo colonizados com R. solani ( $1 \%$ ), e $0,25,0,5,1,1,5$ e 2 g de grãos de arroz colonizados com cada isolado de Trichoderma spp. (ou 0,5, 1, 2, 3 e 4\%). Após uma semana de incubação em sacos de plástico transparentes, à temperatura ambiente, essas misturas foram depositadas na base das plântulas de pepino, com duas semanas de idade. A avaliação foi realizada após uma semana, pela contagem do número de plântulas que sobreviveram em cada tratamento. Nos tratamentos controle, as plântulas receberam substrato com e sem a adição do patógeno. Para cada isolado, o delineamento experimental foi o inteiramente casualizado, com cinco concentrações e uma testemunha somente com o patógeno (seis tratamentos), e cinco repetições. Cada unidade experimental foi constituída por cinco plantas em um saco de plástico. Os dados de cada isolado foram submetidos à análise de variância, e foi testada a significância dos modelos quadrático e linear.

Para a avaliação do efeito da aplicação isolada ou combinadadosisolados de Trichodermaspp., realizou-se outro ensaio em casa de vegetação, com cinco isolados de Trichoderma spp. (IB08, IB13, IB30, IB 34 e IB52), escolhidos aleatoriamente entre os 12 isolados que proporcionaram mais de $85 \%$ de controle do patógeno. Os isolados foram aplicados separadamente ou em combinações de dois ou mais isolados, no total de 27 tratamentos, incluindo os tratamentos-controle (controle sem adição do patógeno, controle com adição do patógeno, IB08, IB13, IB30, IB34, IB52, IB08+IB13, IB08+IB30, IB08+IB34, IB08+IB52, IB13+IB30, IB13+IB34, IB13+IB52, IB30+IB34, IB30+IB52, IB34+IB52, IB08+IB13+IB30, IB08+IB30+IB34, IB08+IB34+IB52， IB18/22+IB30+IB34, IB18/22+ IB34+IB52, IB30+IB34+IB52, IB08+IB30+IB34, IB08+IB30+IB34+IB52, IB13+IB30+IB34+IB52, IB08+IB13+IB30+IB34+IB52). Em $50 \mathrm{~g}$ de substrato comercial Plantmax Ht foram adicionados 2\% (1 g) de grãos de arroz colonizados por Trichoderma spp. e $1 \%(0,5 \mathrm{~g})$ de grãos de trigo colonizados por R. solani. Quando se tratava de uma combinação, os isolados eram aplicados em quantidades iguais até a quantidade final de $1 \mathrm{~g}$ de grãos com antagonistas por repetição. Essas misturas foram incubadas por sete dias à temperatura ambiente, e então foram distribuídas próximas ao colo de plântulas de pepino com duas semanas de idade (aproximadamente $10 \mathrm{~g}$ por planta). Nos tratamentos controle, as plântulas receberam apenas o substrato, com e sem a adição do patógeno. O delineamento experimental e a avaliação desse ensaio foram realizados da mesma forma descrita anteriormente. Os dados de percentagem de tombamento obtidos foram transformados para arc sen $(\mathrm{x} / \mathrm{n})^{0,5}$ e submetidos à análise de variância, e as médias foram comparadas pelo teste de Tukey, a 5\% de probabilidade.

Os 12 isolados de Trichoderma spp. mais eficientes na redução do tombamento (Tabela 1) foram identificados por meio de comparação da região rDNA nuclear, que contém os genes ITS 1 e ITS 2, com sequências da região espaçadora ITS do rDNA, no programa TrichOKEY, disponível em www.isth.info (Druzhinina et al., 2005). Para a extração do DNA genômico, os isolados de Trichoderma spp. foram cultivados por três dias em meio líquido de batata-dextrose, em incubadora tipo $\mathrm{BOD}$, a $27^{\circ} \mathrm{C}$. O micélio foi coletado e lavado duas vezes com água destilada esterilizada. A extração do DNA genômico dos isolados foi feita de acordo com o protocolo II (Vidal et al., 2005). A amplificação da região do rDNA nuclear que contém os genes ITS $1 \mathrm{e}$ ITS 2, foi feita pela combinação dos iniciadores SR6R e LR1 (Lieckfeldt et al., 1999). O programa de PCR consistiu de uma desnaturação inicial de $5 \mathrm{~min}$ a $95^{\circ} \mathrm{C}$, seguida de 35 ciclos de $1 \min$ a $94^{\circ} \mathrm{C}, 2 \min$ a $55^{\circ} \mathrm{C}$, e 
3 min a $72^{\circ} \mathrm{C}$, com uma final de 5 min a $72^{\circ} \mathrm{C}$. Alíquotas de $5 \mu \mathrm{L}$ foram separadas em gel de agarose a $1 \%$ (peso/ volume), em tampão 1XTAE [40 mM Tris, $20 \mathrm{mM}$ ácido acético, 1 mM EDTA (pH 8)], corado com brometo de etídio. O produto dessa reação foi purificado com QIAquick PCR purification Kit (Quiagen) e utilizado na reação de sequenciamento, com os iniciadores já mencionados, o reagente Big Dye terminator (Applied Biosystems) e o sequenciador automático ABI377 (Applied Biosystems).

\section{Resultados e Discussão}

Dos 490 isolados de Trichoderma spp. testados, 44 (9\%) reduziram os sintomas de tombamento causado por $R$. solani em plântulas de pepino. Na Tabela 1, podem ser observados os resultados obtidos no último ensaio, realizado com os 44 isolados selecionados, em que se observou variação na sobrevivência das plantas de $15 \%$, para o tratamento controle, $20 \%$ para os isolados IB05, IB18, IB20 e IB36, e até 100\%, para os isolados IB04, IB13, IB44 e IB60. Para oito dos isolados testados (IB08, IB16, IB24, IB30, B34, IB35, IB52 e IB55), foi observada sobrevivência das plântulas acima de $85 \%$, e para quatro isolados (IB04, IB13, IB44 e IB60) nenhuma planta apresentou sintoma da doença, ou seja, houve total supressão do patógeno (Tabela 1). Vários relatos do potencial de Trichoderma spp. no controle de tombamento de plântulas podem ser encontrados na literatura (Zheng \& Shetty, 1999; Manoranjitham et al., 2000; Lewis e Lumsden, 2001; Patrício et al., 2001; Howel, 2006). Reduções de até $82 \%$ nos sintomas de tombamento em diferentes culturas, inclusive pepino, pela aplicação desses antagonistas, também foram observadas por Manoranjitham et al. (2000) e Lewis e Lumsden (2001). A capacidade do antagonista Trichoderma spp. de proporcionar o controle de fitopatógenos de solo tem sido associada, principalmente, aos mecanismos de micoparasitismo, antibiose e competição (Harman, 2006). Como as mesmas concentrações de patógeno e potencial antagonista foram adicionadas, simultaneamente, a uma porção de substrato comercial e foram incubadas por uma semana antes da aplicação da mistura na base das plantas, a redução da incidência da doença por $9 \%$ dos isolados indica que eles foram capazes de competir com $R$. solani e inibir o patógeno. A adição de antagonistas ao substrato de crescimento de plantas é uma estratégia que pode ser importante no controle de fitopatógenos de solo, porque permite a colonização e o estabelecimento destes agentes antes da sua exposição ao inóculo presente no campo (Harris \& Adkins, 1999). Neste trabalho, procurou-se basear a seleção dos isolados em ensaios realizados in vivo, com sementes e substrato para a produção de mudas comumente empregados por produtores. Portanto, é possível que seja maior a probabilidade de que estes isolados de Trichoderma spp. selecionados tenham um bom desempenho no controle de $R$. solani quando as mudas forem levadas ao campo.

Os tratamentos realizados com os 12 antagonistas, para testar as concentrações mais efetivas dos isolados no controle do tombamento de plântulas de pepino, foram capazes de diminuir em mais de $15 \%$ o número de plantas mortas pelo patógeno. Os tratamentos com os isolados IB08, IB13, IB30 e IB52 proporcionaram o controle do patógeno a partir da dose de $0,5 \%(0,25 \mathrm{~g}$ de grãos de arroz colonizados com cada isolado, em $50 \mathrm{~g}$ de substrato), e não houve, nesses isolados, resposta ao aumento das concentrações adicionadas ao substrato. Para os isolados de Trichoderma spp. IB04, IB16, IB24, IB34, IB35, IB44, IB55e IB60, houve resposta

Tabela 1. Relação dos 44 isolados de Trichoderma spp. que proporcionaram redução no tombamento de plantas de pepino, causado por $R$. solani.

\begin{tabular}{|c|c|c|c|}
\hline Tratamento $^{(1)}$ & $\begin{array}{c}\text { Plantas } \\
\text { sobreviventes } \\
(\%) \\
\end{array}$ & Tratamento & $\begin{array}{c}\text { Plantas } \\
\text { sobreviventes } \\
(\%) \\
\end{array}$ \\
\hline $\mathrm{CP}$ & 15 & IB43 & 50 \\
\hline IB05 & 20 & IB46 & 55 \\
\hline IB18 & 20 & IB64 & 55 \\
\hline IB20 & 20 & IB65 & 65 \\
\hline IB36 & 20 & IB26 & 70 \\
\hline IB10 & 25 & IB51 & 70 \\
\hline IB19 & 25 & IB02 & 75 \\
\hline IB32 & 25 & IB07 & 75 \\
\hline IB45 & 25 & IB38 & 75 \\
\hline IB28 & 30 & IB37 & 75 \\
\hline IB50 & 30 & IB16 & 85 \\
\hline IB03 & 35 & IB24 & 85 \\
\hline IB48 & 35 & IB35 & 85 \\
\hline IB49 & 35 & IB34 & 85 \\
\hline IB47 & 35 & IB30 & 90 \\
\hline IB39 & 35 & IB52 & 90 \\
\hline IB12 & 40 & IB08 & 95 \\
\hline IB21 & 40 & IB55 & 95 \\
\hline IB17 & 45 & IB44 & 100 \\
\hline IB41 & 45 & IB04 & 100 \\
\hline IB42 & 45 & IB13 & 100 \\
\hline IB01 & 50 & IB60 & 100 \\
\hline IB40 & 50 & $\mathrm{CB}$ & 100 \\
\hline
\end{tabular}


quadrática às concentrações do antagonista (Figura 1). O ponto de inflexão para os isolados IB24, IB35, IB44 e IB55 e IB60 foi a concentração de 3\%. Para os isolados IBLF16 e IBLF34, o ponto de inflexão esteve em torno de $4 \%$ e, para os isolados IB04 e IB60, em torno de $2,5 \%$, embora na concentração de $2 \%$ praticamente todos os isolados tenham proporcionado o controle do patógeno, com mais de $75 \%$ de sobrevivência das plântulas. Segundo Hjeljord \& Tronsmo (2003), a aplicação de altas concentrações de propágulos de Trichoderma spp. é necessária para o controle satisfatório de fitopatógenos, embora afirmem que pode ocorrer considerável inibição da germinação dos próprios conídios do antagonista (autoinibição), quando esse gênero é aplicado em doses muito elevadas. Lewis \& Lumsden (2001) também observaram que o controle do tombamento de plântulas de pepino, causado por $R$. solani, variou de acordo com a dose empregada dos antagonistas, e que a maior percentagem de redução no tombamento de plantas de pepino foi obtida
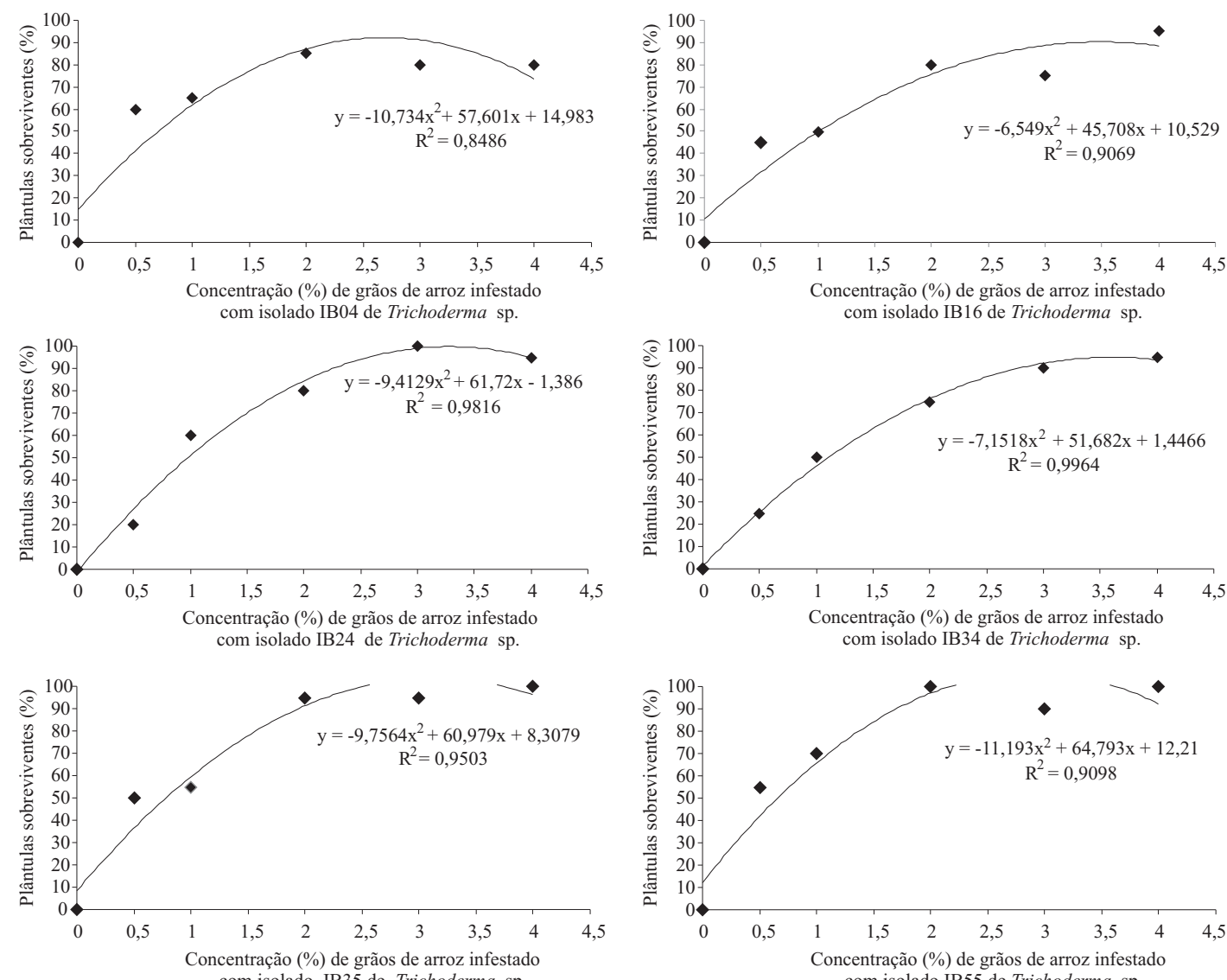
com isolado IB
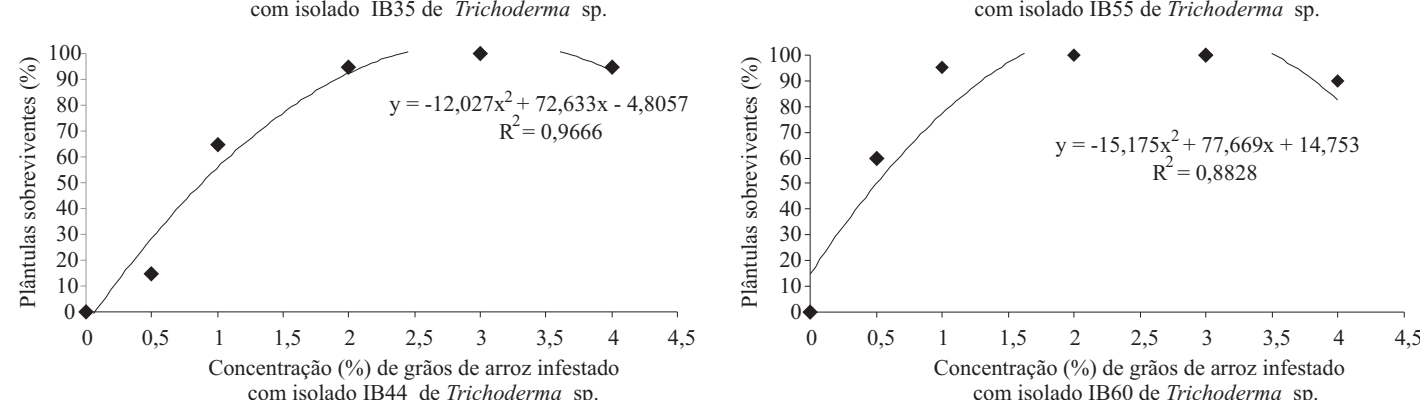

Figura 1. Plântulas de pepino sobreviventes ao tombamento pós-emergência, em resposta à aplicação de concentrações crescentes (\%) de grãos de arroz infestados com isolados de Trichoderma spp. ao substrato. As aplicações dos isolados aos subtratos foi feita juntamente à aplicação de grãos de trigo infestados com o patógeno R.solani, na concentração de $1 \%$. 
com a aplicação de 0,5 e $1 \%$ (v:v). Fravel \& Lewis (2004) observaram a redução da sobrevivência e da atividade saprofítica de $R$. solani, quando isolados de $T$. hamatum e $T$. virens foram incorporados em doses superiores a $1,5 \%$ (v:v). Segundo Hyakumachi (1996), o declínio na viabilidade de $R$. solani encontrase associado às mudanças quantitativas e qualitativas nos propágulos do patógeno. Qualitativamente, pela perda da patogenicidade ou da habilidade de produzir propágulos viáveis e, quantitativamente, pela redução direta dos níveis da população do patógeno, causado por mecanismos de antibiose e parasitismo.

Outros fatores, além da concentração do antagonista, podem interferir no desempenho dos isolados, principalmente os ambientais. Segundo Schmidt et al. (2004), esses fatores são importantes para se determinar a quantidade do agente de controle biológico a ser aplicada para o controle da doença. Esses pesquisadores observaram que a emergência total de plântulas de beterraba ocorreu apenas quando as condições não eram ideais para o desenvolvimento de espécies de Pythium.

Quanto ao efeito da aplicação de combinações de isolados de Trichoderma spp., observou-se que os tratamentos levaram à variação de 12 a $100 \%$ na sobrevivência das plantas (Tabela 2). Não houve diferença significativa na sobrevivência das plantas de pepino ao tombamento causado por $R$. solani, entre os tratamentos coma aplicação individual dos isolados IB13, IB52, IB08 e IB30, com sobrevivências de 100, 100, 96 e $88 \%$ respectivamente. Entretanto, as combinações desses isolados, em geral, resultaram em uma redução significativa no número de plantas sobreviventes, tais como nos tratamentos IB08+IB13+IB30, IB08+IB52, IB08+IB30. Os isolados IB08 e IB34, quando aplicados separadamente, reduziram o tombamento das plantas de pepino em 96 e $60 \%$, respectivamente, e diferiram significativamente do tratamento controle com o patógeno. Entretanto, quando combinados, proporcionaram apenas $52 \%$ de sobrevivência. O mesmo ocorreu com a combinação dos isolados IB08 e IB30. Outra constatação foi a de que a adição dos isolados IB08 e IB13 à combinação IB30+IB34+IB52 causou diminuição significativa no número de plantas sobreviventes, de 100 para $84 \%$. Na combinação com os dois isolados ao mesmo tempo essa redução foi de $44 \%$.

Para algumas das combinações, não se constatou redução ou aumento significativo no número de plantas sobreviventes, quando comparadas à aplicação individual dos isolados, como verificado nos tratamentos IB13+IB52, IB30+IB52, IB13+IB30 e IB08+IB13.

Contudo, a aplicação do isolado IB34 e da combinação IB34+IB52 teve sua eficiência no controle acrescida com a aplicação conjunta do isolado IB30 (combinação IB30+IB34+IB52). Os resultados obtidos, portanto, indicam que a combinação de bons antagonistas pode ou não ser vantajosa ao controle de fitopatógenos, e cuidados devem ser tomados para evitar a mistura de isolados incompatíveis. O mesmo foi observado por Rajan et al. (2002), com a combinação de quatro isolados de Trichoderma spp., considerados excelentes quando aplicados individualmente, mas incapazes de controlar a podridão causada Phytophthora capsici, em pimentapreta, quando aplicados conjuntamente. Raziq \& Fox (2005) também testaram a aplicação combinada

Tabela 2. Efeito da aplicação de isolados de Trichoderma spp., em combinação ou não, no tombamento pós-emergência de plântulas de pepino, causado por $R$. solani $i^{(1)}$.

\begin{tabular}{lc}
\hline Tratamento & Plantas sobreviventes (\%) \\
\hline CB & $100 \mathrm{a}$ \\
IB13 & $100 \mathrm{a}$ \\
IB52 & $100 \mathrm{a}$ \\
IB30+IB34+IB52 & $100 \mathrm{a}$ \\
IB08 & $96 \mathrm{ab}$ \\
IB08+IB30+IB34 & $96 \mathrm{ab}$ \\
IB13+IB52 & $92 \mathrm{abc}$ \\
IB13+IB34 & $92 \mathrm{abc}$ \\
IB13+IB34+IB52 & $88 \mathrm{abcd}$ \\
IB13+IB30+IB34+IB52 & $84 \mathrm{abcde}$ \\
IB30 & $88 \mathrm{abcd}$ \\
IB30+IB52 & $84 \mathrm{abcde}$ \\
IB08+IB30+IB34+IB52 & $84 \mathrm{abcde}$ \\
IB13+IB30 & $76 \mathrm{abcdef}$ \\
IB30+IB34 & $72 \mathrm{abcdef}$ \\
IB08+IB13 & $72 \mathrm{abcdef}$ \\
IB34+IB52 & $64 \mathrm{bcdefg}$ \\
IB34 & $60 \mathrm{cdefg}$ \\
IB13+IB30+IB34 & $60 \mathrm{cdefg}$ \\
IB08+IB13+IB30 & $60 \mathrm{cdefg}$ \\
IB08+IB52 & $56 \mathrm{defg}$ \\
IB08+IB34 & $52 \mathrm{efg}$ \\
IB08+IB13+IB30+IB34+IB52 & $44 \mathrm{fgh}$ \\
IB08+IB30 & $32 \mathrm{ghi}$ \\
IB08+IB34+IB52 & $32 \mathrm{ghi}$ \\
IB08+IB13+IB30+IB34 & $12 \mathrm{hi}$ \\
CP & $0 \mathrm{i}$ \\
CV (\%) & 19,6 \\
\hline & \\
&
\end{tabular}

${ }^{(1)}$ Tratamentos com letras iguais não diferem entre si pelo teste de Tukey, a $5 \%$ de probabilidade, após a transformação dos dados por arc sen $(\mathrm{x} / \mathrm{n})^{0,5}$. ${ }^{(2)} \mathrm{CB}$, controle sem aplicação de microrganismos; $\mathrm{CP}$, controle com patógeno. 
ou não de diferentes antagonistas no controle da podridão-da-raiz de morango, causada por Armillaria, e constataram que alguns isolados de T. harzianum e $T$. hamatum foram mais eficientes no controle do patógeno, quando aplicados individualmente, embora outros dois isolados, um de T. harzianum e um de $T$. viride, tenham sido mais eficientes quando combinados. Segundo Schmidt et al. (2004), há necessidade de se conhecer o perfil ambiental do inóculo misto, para se garantir um controle mais satisfatório da doença, pois a combinação apropriada encontra-se associada à escala de adaptação de cada participante às condições químicas, físicas e biológicas do ambiente.

Três isolados foram identificados como T. hamatum (IB08, IB30, IB60), dois como T. harzianum (IB34, IB35), um como T. atroviride (IB13), dois como T. spirale (IB16, IB24) e um como T. asperellum (IB44). A identificação das espécies dos outros três isolados (IB04, IB52, IB55) não foi possível, em razão da necessidade de se complementarem as informações com o sequenciamento do marcador tefl (grande intron).

Todas as espécies identificadas são conhecidas e utilizadas no controle biológico de fitopatógenos, de acordo com dados publicados em literatura especializada, inclusive no controle de $R$. solani (Cotxarrera et al., 2002; Hermosa et al., 2004; Brunner et al., 2005; Shalini et al., 2006). Segundo Carpenter et al. (2005), a maioria das preparações utilizadas no biocontrole de fitopatógenos é feita com as espécies $T$. atroviride e $T$. harzianum, embora os autores reconheçam o potencial de T. hamatum como agente de biocontrole, mesmo sendo uma espécie menos conhecida. Lisboa et al. (2007) observaram que, de 36 antagonistas selecionados contra Botrytis cinerea, 24 foram classificados como T. harzianum. Shalini et al. (2006) observaram que, de 17 isolados antagonistas a $R$. solani estudados, três foram identificados como T. harzianum. Em estudo sobre a biodiversidade de isolados de Trichoderma spp., no Sudeste da Ásia, entre 78 isolados identificados, 37 pertenciam à espécie T. harzianum, 16 a T. virens, oito a T. spirale, três a $T$. koningii, três a $T$. aureoviride, quatro a T. asperellum, dois a Hypocrea jecorina, dois a T. viride, um a $T$. hamatum e um a $T$. ghanense (Kubicek et al., 2003). Em outro estudo, desenvolvido no Brasil, Lima (2002) identificou 46 isolados de Trichoderma spp., provenientes de solo do cerrado, e constatou que a espécie mais frequentemente isolada foi T. harzianum
(34 isolados), seguida por T. asperellum (4 isolados), T. koningii ( 3 isolados) e $T$. spirale ( 2 isolados).

\section{Conclusões}

1. Dos 490 isolados de Trichoderma spp. testados, 44 são capazes de reduzir entre 5 e $100 \%$ os sintomas de tombamento causado por Rhizoctonia solani, em plântulas de pepino.

2. Em geral, concentrações acima de $2 \%$ proporcionam controle mais eficiente dos sintomas causados por $R$. solani.

3. A maioria das combinações é menos eficiente que os isolados aplicados separadamente, no controle do tombamento.

4. Os isolados mais eficientes no controle da doença são os de T. hamatum, T. harzianum, T. atroviride, T. spirale e de T. asperellum.

\section{Referências}

BRUNNER, K.; ZEILINGER, S.; CILIENTO, R.; WOO, S.L.; LORITO, M.; KUBICEK, C.P.; MACH, R.L. Improvement of the fungal biocontrol agent Trichoderma atroviride to enhance both antagonism and induction of plant systemic disease resistance. Applied and Environmental Microbiology, v.71, p.3959-3965, 2005.

CARPENTER, M.A.; STEWART, A.; RODGWAY, H.J. Identification of novel Trichoderma hamatum genes expressed during mycoparasitism using subtractive hybridisation. FEMS Microbiology Letters, v.251, p.105-112, 2005.

COTXARRERA, L.; TRILLAS-GAY, M.I.; STEINBERG, C.; ALABOUVETTE, C. Use of sewage sludge compost and Trichoderma asperellum isolates to suppress fusarium wilt of tomato. Soil Biology \& Biochemistry, v.34, p.467-476, 2002.

DRUZHININA, I.; KUBICEK, C.P. Species concepts and biodiversity in Trichoderma and Hypocrea: from aggregate species to species clusters? Journal of Zhejiang University Science, v.6, p.100-112, 2005.

DRUZHININA, I.S.; KOPCHINSKIY, A.G.; KOMON, M.; BISSETT, J.; SZAKACS, G.; KUBICEK, C.P. An oligonucleotide barcode for species identification in Trichoderma and Hypocrea. Fungal Genetics and Biology, v.42, p.813-828, 2005.

FALTIN, F.; LOTTMANN, J.; GROSCH, R.; BERG, G. Strategy to select and assess antagonistic bacteria for biological control of Rhizoctonia solani Kühn. Canadian Journal of Microbiology, v.50, p.811-820, 2004.

FRAVEL, D.R.; LEWIS, J.A. Effect of label and sublabel rates of metam sodium in combination with Trichoderma hamatum, T. harzianum, T. virens, and T. viride on survival and growth of Rhizoctonia solani. Phytoparasitica, v.32, p.111-118, 2004.

GOULART, A.C.P. Efeito do tratamento de sementes de algodão com fungicidas no controle do tombamento de plântulas 
causado por Rhizoctonia solani. Fitopatologia Brasileira, v.27, p.399-402, 2002.

GRIGOLETTI JÚNIOR, A.; SANTOS, A.F.; AUER, C.G. Perspectivas do uso do controle biológico contra doenças florestais. Revista Floresta, v.30, p.155-165, 2000.

HARMAN, G.E. Overview of mechanisms and uses of Trichoderma spp. Phytopathology, v.96, p.190-194, 2006.

HARMAN, G.E.; HOWELL, C.R.; VITERBO, A.; CHET, I.; LORITO, M. Trichoderma species - opportunistic, avirulent plant symbionts. Natural Reviews. Microbiology, v.2, p.43-56, 2004.

HARRIS, A.R.; ADKINS, P.G. Versatility of fungal and bacterial isolates for biological control of damping-off disease caused by Rhizoctonia solani and Pythium spp. Biological Control, v.15, p.10-18, 1999.

HERMOSA, M.R.; KECK, E.; CHAMORRO, I.; RUBIO, B.; SANZ, L.; VIZCAINO, J.A.; GRONDONA, I.; MONTE, E. Genetic diversity shown in Trichoderma biocontrol isolates. Mycological Research, v.108, p.897-906, 2004.

HJELJORD, L.G.; TRONSMO, A. Effect of germination initiation on competitive capacity of Trichoderma atroviride P1 conidia. Phytopathology, v.93, p.1593-1598, 2003.

HOWELL, C.R. Effect of seed quality and fungicide/ Trichoderma spp. seed treatments on pre- and post-emergence damping-off in cotton. Phytopathology, v.97, p.66-71, 2006.

HYAKUMACHI, M. Suppression and prevention in Rhizoctonia disease: mechanisms involved in disease decline. In: SIMPÓSIO DE CONTROLE BIOLÓGICO, 5., 1996, Foz do Iguaçu. Anais. Curitiba: PJ Comunicações e Eventos, 1996. p.140-149.

KUBICEK, C.P.; BISSETT, J.; DRUZHININA, I.; KULLNIG-GRADINGER, C.; SZAKACS, G. Genetic and metabolic diversity of Trichoderma: a case study on South-East Asian isolates. Fungal Genetics and Biology, v.38, p.310-319, 2003.

LEWIS, J.A.; LUMSDEN, R.D. Biocontrol of damping-off of greenhouse-grown crops caused by Rhizoctonia solani with a formulation of Trichoderma spp. Crop Protection, v.20, p.49-56, 2001.

LIECKFELDT, E.; SAMUELS, G.J.; NIRENBERG, H.I.; PETRINI, O. A morphological and molecular perspective of Trichoderma viride: is it one or two species? Applied and Environmental Microbiology, v.65, p.2418-2428, 1999.

LIMA, A.L. Caracterização morfológica, molecular e bioquímica de Trichoderma spp., isolados do solo do Cerrado. 2002. 74p. Tese (Doutorado) - Universidade de Brasília, Brasília.
LISBOA, B.B.; BOCHESE, C.C.; VARGAS, L.K.; SILVEIRA, J.R.P.; RADIN, B.; OLIVEIRA,A.M.R. Eficiência de Trichoderma harzianum e Gliocladium viride na redução da incidência de Botrytis cinerea em tomateiro cultivado sob ambiente protegido. Ciência Rural, v.37, p.1255-1260, 2007.

MANORANJITHAM, S.K.; PRAKASAM, V.; RAJAPPAN, K.; AMUTHA, G. Effect of two antagonists on damping-off disease of tomato. Indian Phytopathology, v.53, p.441-443, 2000.

MARQUES, P.A.A.; BALDOTTO, P.V.; SANTOS, A.C.P.; OLIVEIRA, L. de. Qualidade de mudas de alface formadas em bandejas de isopor com diferentes números de células. Horticultura Brasileira, v.21, p.649-651, 2003.

PATRICIO, F.R.A.; KIMATI, H.; BARROS, B.C. Seleção de isolados de Trichoderma spp. antagônicos a Pythium aphanidermatumeRhizoctonia solani.SummaPhytopahtologica, v.27, p.223-229, 2001.

PERES, F.; MOREIRA, J.C.; CLAUDIO, L. Os impactos dos agrotóxicos sobre a saúde e o ambiente. Ciência \& Saúde coletiva, v.12, p.4, 2007.

RAJAN, P.P.; SARMA, Y.R.; ANANDARAJ, M. Management of foot rot disease of black pepper with Trichoderma species. Indian Phytopathology, v.55, p.17-21, 2002.

RAZIQ, F.; FOX, R.T.V. Combinations of fungal antagonists for biological control of Armillaria root rot of strawberry plants. Biological Agriculture \& Horticulture, v.23, p.45-57, 2005.

SCHMIDT, C.S.; AGOSTINI, F.; LEIFERT, C.; KILLHAM, K.; MULLINS, C.E. Influence of soil temperature and matric potential on sugar beet seedling colonization and suppression of Pythium damping-off by the antagonistic bacteria Pseudomonas fluorescens and Bacillus subtilis. Phytopathology, v.94, p.351-363, 2004

SHALINI; NARAYAN, K.P.; LATA; KOTASTHANE, A.S. Genetic relatedness among Trichoderma isolates inhibiting a pathogenic fungi Rhizoctonia solani. African Journal of Biotechnology, v.5, p.580-584, 2006.

VIDAL, M.S.; SUASSUNA, N.D.; BEZERRA, C. de S.; MENESES, C.H.S.G. Comparação entre protocolos de extração de DNA para Amphobotrys ricini. Campina Grande: Embrapa Algodão, 2005. 5p. (Embrapa Algodão. Comunicado Técnico, 239).

WOO, S.L.; SCALA, F.; RUOCCO, M.; LORITO, M. The molecular biology of the interactions between Trichoderma spp., phytopathogenic fungi, and plants. Phytopathology, v.96, p.181-185, 2006.

ZHENG, Z.X.; SHETTY, K. Effect of apple pomace-based Trichoderma inoculants on seedling vigour in pea (Pisum sativum) germinated in potting soil. Process Biochemistry, v.34, p.731-735, 1999. 